\title{
Supplemental diagnosis and molecular taxonomy of Myxobolus diaphanus (Fantham, Porter et Richardson, 1940) (Myxozoa) parasitizing Fundulus diaphanus (Cyprinodontiformes) in Nova Scotia, Canada
}

\author{
David K. Cone ${ }^{1}$ and Russell H. Easy ${ }^{2}$ \\ ${ }^{1}$ Department of Biology, Saint Mary's University, Halifax, Nova Scotia, B3H 3C3, Canada; \\ ${ }^{2}$ National Research Council, Institute for Marine Biosciences, Halifax, Nova Scotia, B3H 3Z1, Canada
}

Key words: Myxozoa, Myxobolus diaphanus, supplemental diagnosis, Fundulus diaphanus, Nova Scotia

\begin{abstract}
Myxobolus diaphanus (Fantham, Porter et Richardson, 1940) was found in banded killifish Fundulus diaphanus (Lesueur) at several freshwater localities in Nova Scotia, including the type locality at the mouth of the Salmon River, Guysborough County. The new material, the first to be reported in 64 years, was used to supplement information on spore morphology, to document the site of development in the tissue, and to compare sequence data of the 18S rDNA to other studied myxobolids. Plasmodia with developed spores occurred in loose connective tissue of the head, the dermis (particularly in the roof of the mouth and at the base of fins), surface of the brain and ovary, muscle epimysium, and the submucosa of the intestine. Developed plasmodia containing spores were also found free in the lumen of the vena cava and within fluid-filled spaces of the skull, mandible and lower jaw. A phylogenetic analysis using 18S rDNA (878 bp) placed $M$. diaphanus in a terminal clade containing certain freshwater species of Henneguya, all of which occur in North America and have elongate spore bodies.
\end{abstract}

Myxobolus diaphanus (Fantham, Porter et Richardson, 1940) (Myxozoa) was described from banded killifish Fundulus diaphanus (Lesueur) in Nova Scotia 64 years ago and has not been reported in subsequent parasite surveys (Wiles 1975, Hoffman 1999). During necropsies of this host species from Nova Scotia, including the type locality, infections of $M$. diaphanus were encountered. The new material is used to provide detailed information on spore morphology, the site of tissue development, and sequence data of $18 \mathrm{~S}$ rDNA.

\section{MATERIALS AND METHODS}

Samples of adult banded killifish were collected from three freshwater localities: Vinegar Lake, Nova Scotia (4440'30'N, 6402'57'W) (July 25, 1996), Indian Lake, Nova Scotia

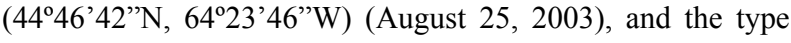
locality of $M$. diaphanus at the mouth of St. Mary's River,

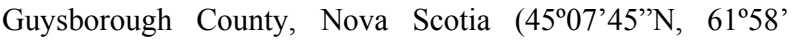
37 'W) (June 2, 1997). Baited minnow traps or a beach seine were used to catch the fish, which were then fixed in $10 \%$ formalin. Fixed fish were cut with a sharp scalpel into 10-12 cross-sections and the pieces were embedded with a cut face down into one or two plastic embedding moulds. A single histological section that included tissue from all pieces was prepared at $7 \mu \mathrm{m}$, mounted on a clean glass slide, dewaxed in xylene, rehydrated, stained in Giemsa for $3 \mathrm{~h}$, dehydrated in ethanol, cleared in xylene, and mounted in Permount. The method produced sections of all principal organs on one or two slides (Marcogliese and Cone 2001). Histological sections were used to describe the form and distribution of plasmodia in host tissues as well as to estimate the prevalence of the parasite at each locality.

The taxonomic studies focused on samples of $F$. diaphanus from Indian Lake, Nova Scotia. The contents of three myxozoan cysts were prepared as temporary mounts in $1 \%$ agar and used to obtain morphometric measurements and digitized images of spores. Fresh spores were stained in Lugol's iodine (for detection of the iodinophilous vacuole) and methylene blue (for detection of the mucous coat). Voucher specimens of parasites in histological sections, including ones from the type locality, have been deposited in the United States National Parasite Collection, Beltsville, Maryland 20705, USA (accession number 95334).

A sample of fresh spores from three large cysts in the roof of the mouth of a fish from Indian Lake, Nova Scotia, were examined microscopically to confirm the presence of $M$. diaphanus and then processed for study of the $18 \mathrm{~S}$ rDNA using the methods of Akaishi et al. (2004) and primers listed in Table 1. Sequencher (Version 4.0.5) (Gene Codes Corporation, Ann Arbor, Michigan) was used to edit sequence data and produce contiguous alignments. Sequences were aligned using Clustal X (Thompson et al. 1997) and sequence data from the 18S rDNA of myxobolid species in GenBank was used for a complete alignment. Sequences were subjected to BLAST (Altschul et al. 1990) searches against those sequences in GenBank (NCBI). Phylogenetic analyses were conducted using PAUP, version 4.0b10 (Swofford 2001) and included parsimony, maximum likelihood, and distance methods. The phylogeny was calculated using neighbour joining methods and bootstrap analysis with 1,000 replicates. Sequences used in the alignment were Ceratomyxa shasta 
Table 1. Primer sequences used to amplify SSU 18S rDNA from spores of Myxobolus diaphanus from Fundulus diaphanus in Indian Lake, Nova Scotia.

\begin{tabular}{|l|l|l|}
\hline Primer & Sequence & Reference \\
\hline MX5 & 5' ctgcggacggctcagtaaatcagt 3' & Andree et al. 1998 \\
MX3 & 5' ccaggacatcttagggcatcacaga 3' & Andree et al. 1998 \\
18g & 5' ggtagtagcgacgggcggtgtg 3' & Hillis and Dixon 1991 \\
18r & 5, ctacggaaacttgttacg 3' & Whipps et al. 2003 \\
Myxgp2f & 5' tggataaccgtgggaaa 3' & Kent et al. 1998 \\
ACT1r & 5, aattcacctctcgctgcca 3' & Hallett and Diamant 2001 \\
ACT3f & 5' catggaacgaacaat & Hallett and Diamant 2001 \\
\hline
\end{tabular}

(AF001579), Myxidium truttae (AF201374), Myxidium sp. (U13829), Henneguya lesteri (AF306794), H. doori (U37549), H. ictaluri (AF195510), H. exilis (AF021881), H. zschokkei (AF378344), H. salminicola (AF031411), Myxobolus osburni (AF378338), M. spinacurvatura (AF378341), M. ichkeulensis (AF378337), M. lentisuturalis (AY119688), M. xiaoi (AF186843), M. portucalensis (AF085182), M. cerebralis (U96492), M. insidiosus (U96494), M. neurobius (AF085180), M. ellipsoides (AF085178), M. drjagini (AF085179), M. arcticus (AF085176), M. bramae (AF085177), M. sandrae (AF085181), M. pseudodispar (AF380143), M. musculi (AF380141), M. cyprini (AF380140), M. hungaricus (AF448444), M. pendula (AF378340), M. pellicides (AF378339), M. bibullatus (AF378336), M. elegans (AF448445), M. algonquinensis (AF378335), M. episquamalis (AY129312), M. longisporus (AY364637), M. obesus (AY325286), M. intimus (AY325285), M. muelleri (AY325284), M. acanthogobii (AY541585), M. bizerti (AY129318), M. cultus (AB121146), M. bononiense (AY278563), M. kubanicum (AY165183), M. rotundatus (AY165180), M. exiguus (Y129317), M. dispar (AF507972), M. basilamellaris (AF507971), M. impressus (AF507970), M. macrocapsularis (AF507969), M. squamalis (U96495), M. smithi (AF186841), M. siddalli (AF186840), M. pseudokoi (AF186839), M. martini (AF186836), and $M$. bartai (AF186835).

\section{RESULTS}

Prevalence of infection in banded killifish from Vinegar Lake, Indian Lake, and the Salmon River, was $73.3 \%(11 / 15), 93.3 \%(14 / 15)$, and 78.5\% (11/14), respectively.

Plasmodia of $M$. diaphanus were round to elongate, up to $0.5 \mathrm{~mm}$ in maximum length, and typically embedded in loose connective tissue of the skull, the skin dermis (particularly in the roof of the mouth and the base of fins) (Fig. 1), peritoneum, the surface of the brain and ovary, muscle epimysium, and submucosa of the intestine (Fig. 2). Plasmodia were without a distinct ectoplasm or endoplasm, with mono- and disporoblasts and developed spores distributed loosely throughout a fluidfilled matrix with little debris (Figs. 1, 2). Plasmodia occurred frequently in aggregations within spaces of the skull (Fig. 3) as well as within pooled blood of the vena cava (Fig. 4).
Fresh spores (from fish in Indian Lake, Nova Scotia) were elongate pyriform in frontal view (Fig. 5), lenticular in lateral view (Fig. 5), and often with two distinct sutural ridge folds posteriorly (Figs. 5, 6). Spores were $19.1 \pm 1.3(17.0-21.8)(\mathrm{n}=11)$ long, $7.2 \pm 0.5(6.8-7.7)$ $(\mathrm{n}=11)$ wide, and $5.8(\mathrm{n}=1)$ thick, with a length to width ratio of $1: 2.66 \pm 0.25(1: 2.29-1: 3.02)(\mathrm{n}=11)$. The polar capsules were elongate pyriform, sometimes slightly unequal in length, with a distinct, long neck that converged anterior without crossing. The polar capsules were $8.5 \pm 0.5(7.4-9.8)(\mathrm{n}=21)$ long and $2.3 \pm 0.2$ (1.9-2.7) $(\mathrm{n}=21)$ wide, and contained 7-10 filament coils arranged tightly and nearly perpendicular to the long axis of the capsule. The sporoplasm often contained two distinct nuclei and a granular cytoplasm. An iodinophilous vacuole and mucous envelope were absent in fresh material. In Giemsa-stained histological sections, spores contained a prominent non-iodinophilous vacuole.

Molecular methods produced an 878 bp sequence of the 18S rDNA (GenBank No. AY950664). Myxozoan general primers $18 \mathrm{e}-18 \mathrm{r}$ and MX5-MX3 (Table 1) were used to amplify SSU $18 \mathrm{~S}$ rDNA from $M$. diaphanus. The MX5-MX3 primer set was inconsistent in producing a PCR product for sequencing, therefore sequence data for the present analysis were obtained using the $18 \mathrm{e}-18 \mathrm{r}$ primers. The resulting PCR product was sequenced using Myxobolus specific and non-specific primers Myxgp2f-ACT1r and ACT3f-MX3. The bootstrap of this information with published sequences produced a tree topology with five principle clades (Fig. 7). Myxobolus diaphanus is a member of a clade arising basally within the tree, and within a terminal clade composed of various North American freshwater species of Henneguya (Fig. 7).

\section{DISCUSSION}

Fantham et al. (1940) described Myxobolus diaphanus from a smear of a small cyst on the surface of the testes of an adult banded killifish collected from a freshwater backwater at the mouth of the Salmon River, Guysborough County, Nova Scotia. Seventy-eight percent of fish examined from the type locality in the present study were infected with $M$. diaphanus. The 


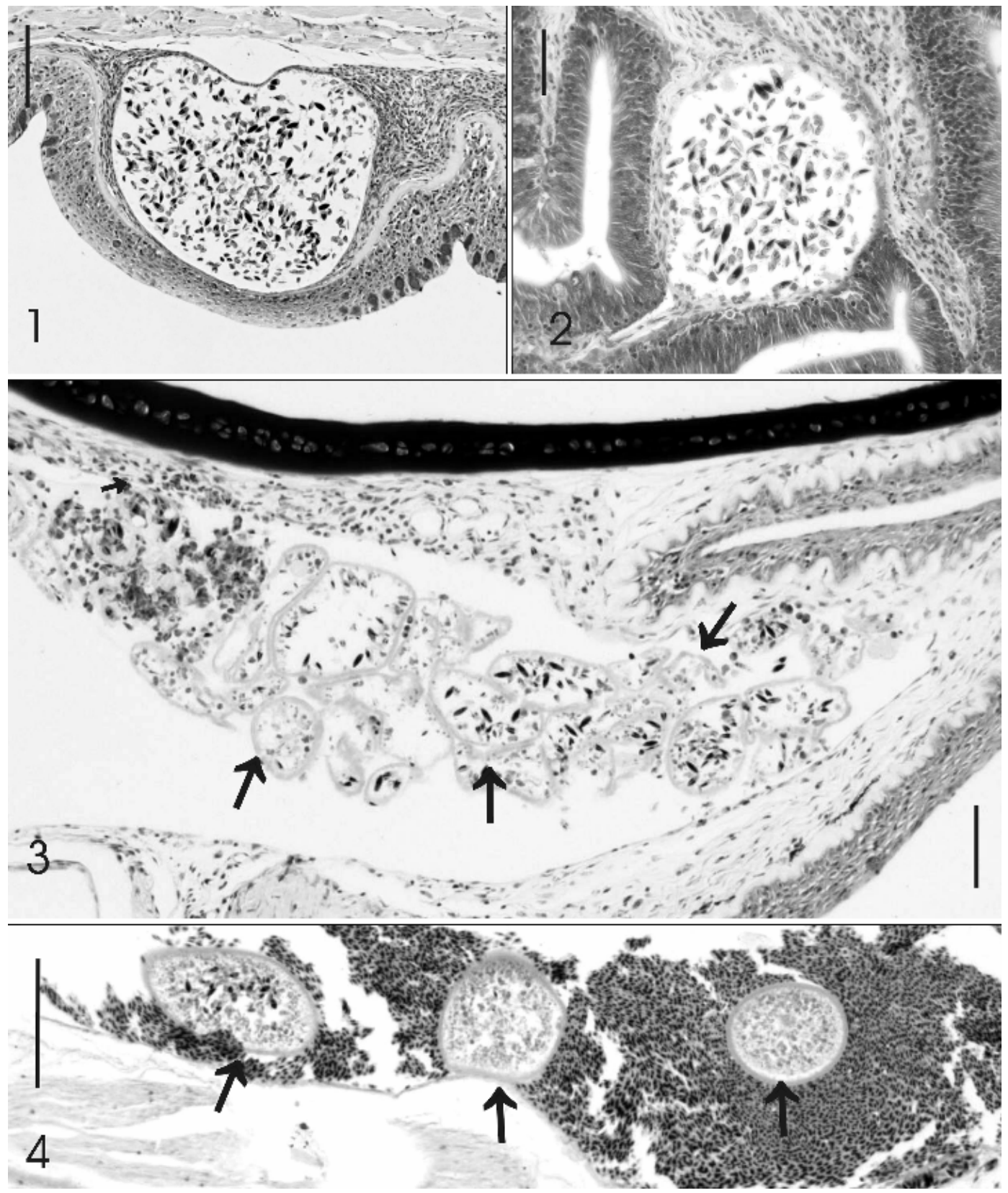

Figs. 1-4. Giemsa-stained histological sections of plasmodia of Myxobolus diaphanus in different tissues of Fundulus diaphanus. Fig. 1. Plasmodium within dermis of the roof of the mouth. Fig. 2. Plasmodium within submucosa of the intestinal wall. Fig. 3. Aggregation of plasmodia (arrows) within fluid-filled space of the skull. Fig. 4. Plasmodia (arrows) within pooled blood of the vena cava. Scale bars: Figs. 1, $4=100 \mu \mathrm{m}$; Figs. 2, $3=50 \mu \mathrm{m}$.

relatively high prevalence of infection of $M$. diaphanus in Vinegar Lake and Indian Lake suggests that this parasite is common and widespread in this host. The parasite has not been encountered in any other local fish species necropsied to date and thus appears specific to banded killifish. The present study is the first report of the parasite in 64 years.

As originally described, $M$. diaphanus has relatively large, elongate-oval spores, with distinct sutural ridge folds in the posterior of the spore, and a prominent vacuole in the sporoplasm of Giemsa-stained material. The new material reveals that the polar capsules have a distinctly narrow "neck" region and the number of filament coils is $7-10$ rather than $11-15$ as originally reported by Fantham et al. (1940). Furthermore, the development of plasmodia is not limited to testicular tissue. The parasite normally develops in loose connective tissue and consequently is found in a variety of different organs. 


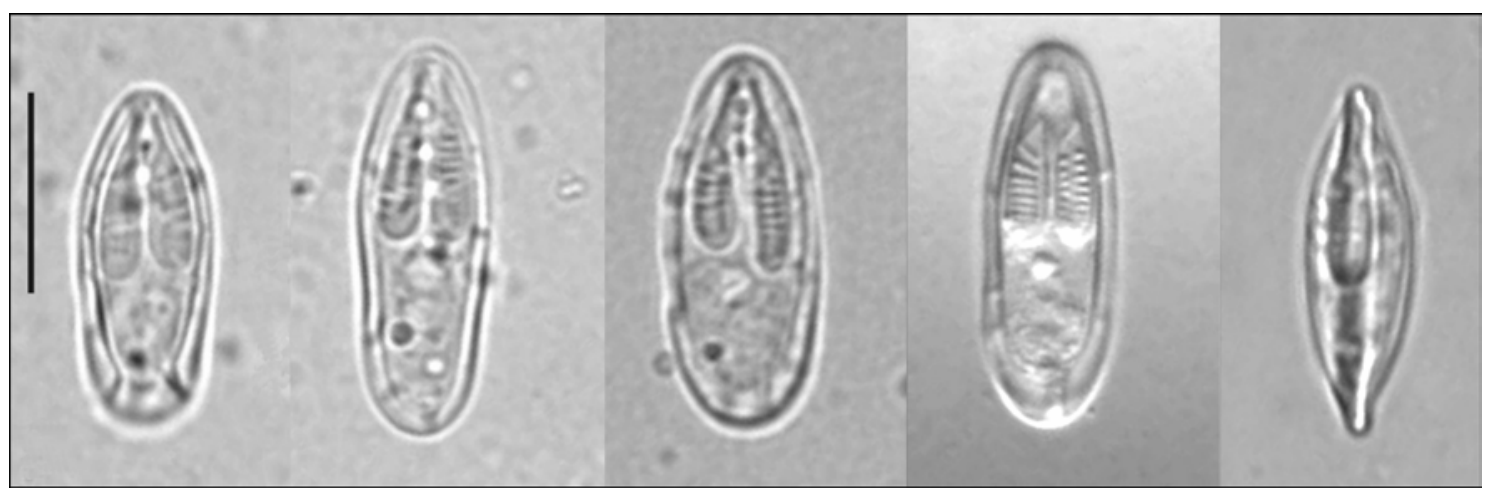

Fig. 5. Fresh spores of Myxobolus diaphanus photographed with interference contrast and bright field optics. Scale bar $=10 \mu \mathrm{m}$.

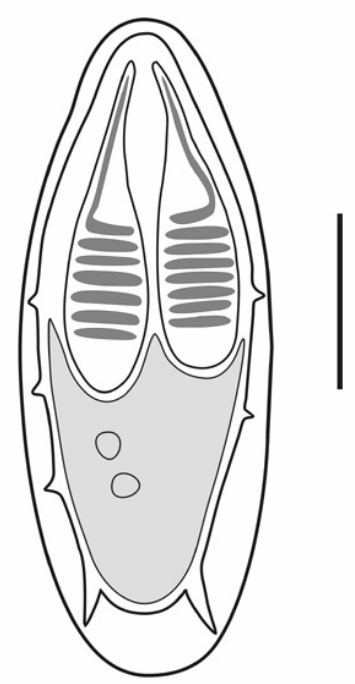

Fig. 6. Drawing of typical spore of Myxobolus diaphanus. Scale bar $=5 \mu \mathrm{m}$.

The presence of spore-filled plasmodia lying free in tissue spaces of the head and within pooled blood of the vena cava is unusual for histozoic myxobolids, but in this case appears to involve normal development. The fact that these plasmodia contained developed spores indicates they are not early development stages en route to connective tissue. The aggregation and folded appearance of plasmodia within the skull are reminiscent of those reported of Myxobolus conei described from the lumen of bile ducts of Pseudocaranx dentex in marine waters of Australia (Lom and Dyková 1994).

Phylogenetic analysis of the $18 \mathrm{~S}$ rDNA sequence data places $M$. diaphanus in a terminal clade that in- cludes three species of Henneguya (H. doori, H. exilis and $H$. ictaluri), all from freshwater fishes in North America. This placement is not that surprising, given the view that Henneguya, as presently defined, is not a valid myxobolid taxon (Kent et al. 2001, Bahri et al. 2003), with two filamentous valvular extensions characteristic of the genus having apparently arisen independently several times during the complex history of myxobolids. What is interesting is that the spore body of M. diaphanus and the three species of Henneguya are all elongate oval. This raises the possibility that the distinct sutural ridge folds observed in M. diaphanus are structurally homologous to the valvular filamentous extensions of Henneguya.

Myxobolus diaphanus resembles Myxobolus subtecalis (Bond, 1938) from mummichog Fundulus heteroclitus (Linnaeus) in coastal waters of northeastern North America. The two species occupy similar sites in their respective hosts and both have relatively large pyriform spores with distinct sutural ridge folds posteriorly. Based on the original species description of M. subtecalis, fresh spores of $M$. diaphanus are generally longer (17-21.8 $\mu \mathrm{m}$ versus $15-18 \mu \mathrm{m})$ while having similar spore widths and polar capsules. What will be interesting to determine is the similarity in the $18 \mathrm{~S}$ rDNA between the two species given their comparable spore morphologies and affinity for two closely related hosts. This may be a case of the limited radiation of a myxobolid from freshwater to a marine host (Lom and Dyková 1994, Bahri et al. 2003).

Acknowledgement. This work was funded by an NSERC Discovery Grant awarded to D.K. Cone. 


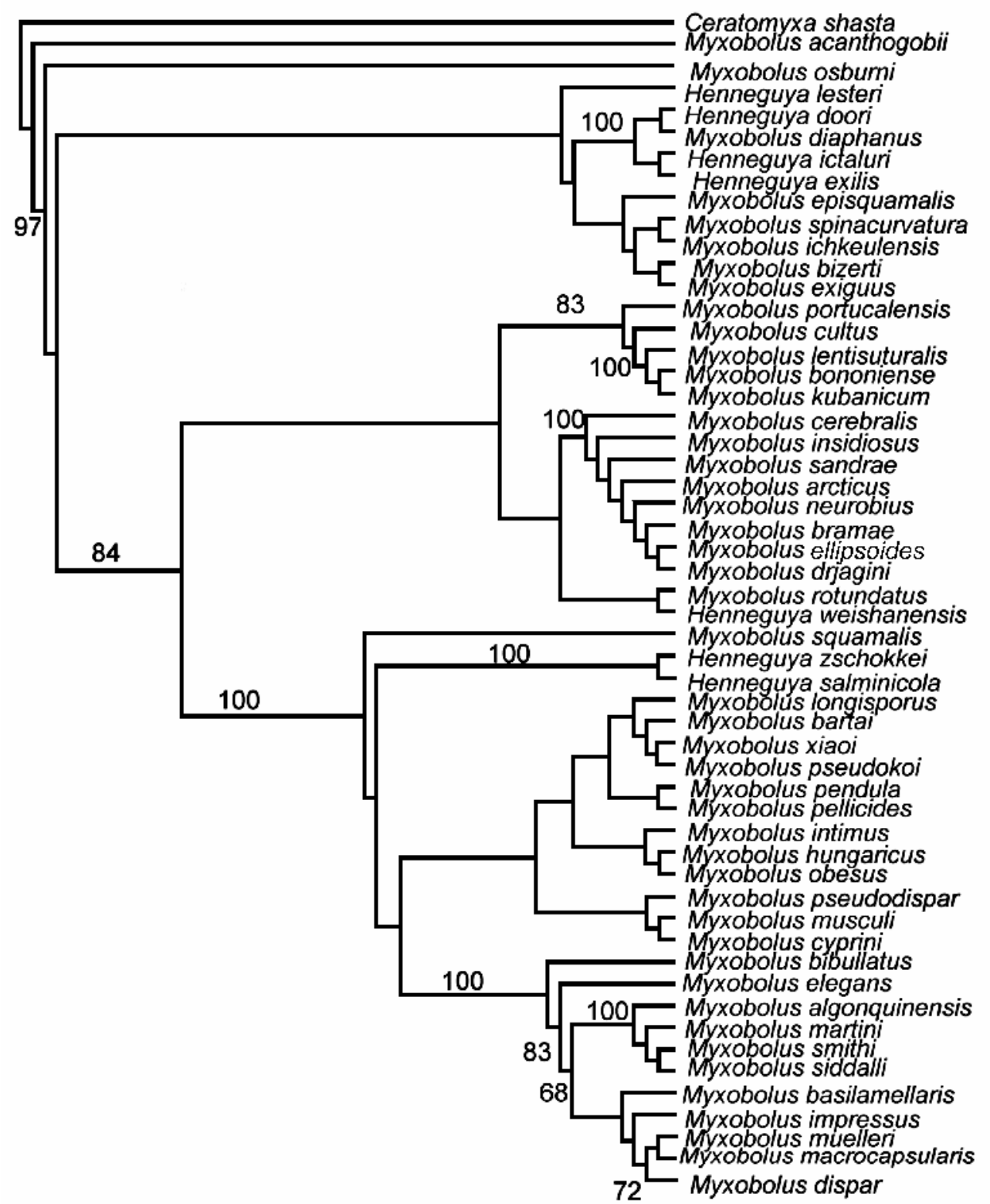

Fig. 7. Neighbour-joining analysis of small subunit ribosomal DNA sequences of Myxobolus diaphanus in relation to related myxobolids.

\section{REFERENCES}

AKAISHI F., EASY R., ST-JEAN S., COURTENAY S., OLIVEIRA RIBEIRO C.A., CONE D.K. 2004: Supplemental diagnosis of Kudoa funduli (Myxozoa) parasitizing Fundulus heteroclitus (Cyprinodontidae) from coastal northeastern North America. J. Parasitol. 90: 477-480.

ALTSCHUL S.F., GISH W., MILLER W., MYERS E.W., LIPMAN D.J. 1990: Basic local alignment search tool. J. Mol. Biol. 215: 403-410.

ANDREE K.B., MacCONNELL E., HEDRICK R.P. 1998: A nested polymerase chain reaction for the detection of genomic DNA of Myxbolus cerebralis in rainbow trout $\mathrm{On}$ corhynchus mykiss. Dis. Aquat. Org. 34: 145-154.
BAHRI S., ANDREE K.B., HEDRICK R.P. 2003: Morphological and phylogenetic studies of marine Myxobolus spp. from mullet in Ichkeul Lake, Tunisia. J. Eukaryot. Microbiol. 50: 463-470.

BOND F.F. 1938: Cnidosporidia from Fundulus heteroclitus Lin. Trans. Am. Microsc. Soc. 57: 107-122.

FANTHAM H.B., PORTER A., RICHARDSON L.R. 1940: Some more myxosporidia observed in Canadian fishes. Parasitology 32: 333-353.

HALLETT S.L., DIAMANT A. 2001: Ultrastructure and small-subunit ribosomal DNA sequence of Henneguya lesteri n. sp. (Myxosporea), a parasite of sand whiting Sillago 
analis (Sillaginidae) from the coast of Queensland, Australia. Dis. Aquat. Org. 46: 197-212.

HILLIS D.-M., DIXON M.T. 1991: Ribosomal DNA: molecular evolution and phylogenetic inference. Quart. Rev. Biol. 66: 411-453.

HOFFMAN G.L. 1999: Parasites of North American Freshwater Fishes. Second Edition. Comstock Publishing Associates, Cornell University Press, Ithaca and London, $539 \mathrm{pp}$.

KENT M.L., ANDREE K.B., BARTHOLOMEW J.L., ElMATBOULI M., DESSER S.S., DEVLIN R.H., FEIST S.W., HEDRICK R.P., HOFFMAN R.W., KHATTRA J., HALLETT S.L., LESTER R.J.G., LONGSHAW M., PALENZUELA O., SIDDALL M.E., XIAO C. 2001: Recent advances in our knowledge of the Myxozoa. J. Eukaryot. Microbiol. 48: 395-413.

KENT M.L., KHATTRA J., HERVIO D.M.L., DEVLIN R.H. 1998: Ribosomal DNA sequence analysis of isolates of the PKX myxosporean and their relationship to members of the genus Sphaerospora. J. Aquat. Anim. Health 10: 12 21.

LOM J., DYKOVÁ I. 1994: Studies on protozoan parasites of Australian fishes III. Species of the genus Myxobolus Bütschli, 1882. Eur. J. Protistol. 30: 431-439.
MARCOGLIESE D.J., CONE D.K. 2001: Structure of myxozoan communities parasitizing Notropis hudsonius (Cyprinidae) at selected localities on the St. Lawrence River, Quebec: possible effects of urban effluents. J. Parasitol. 87: 951-956.

SWOFFORD D.L. 2001: PAUP*. Phylogenetic analysis using parsimony (*and other methods), Version 4. Sinauer Associates, Sunderland, Massachusetts, USA.

THOMPSON J.D., GIBSON T.J., PLEWNIAK F., JEANMOUGIN F., HIGGINS D.G. 1997: The Clustal X windows interface: flexible strategies for multiple sequence alignment aided by quality analysis tools. Nucleic Acids Res. 24: 4876-4882.

WHIPPS C.-M., ADLARD R.D., BRYANT M.S., KENT M.L. 2003: Two unusual myxozoans, Kudoa quadricornis n. sp. (Multivalvulida) from the muscle of godspotted trevally (Carangoides fulvoguttatus) and Kudoa permulticapsula n. sp. (Multivalvulida) from the muscle of Spanish mackerel (Scomberomorus commersoni) from the Great Barrier Reef, Australia. J. Parasitol. 89: 168-173.

WILES M. 1975: Parasites of Fundulus diaphanus (LeSueur) (Pisces: Cyprinodontidae) in certain Nova Scotia freshwaters. Can. J. Zool. 53: 1578-1580.

Accepted 1 April 2005 